3. Pain and tenderness of the right hypochondrium, indicating hepatic disease.

4. Repeated chills, pyrexia, and diaphoresis, indicating a septic process likely to prove fatal.

5. The marked accessions -and remissions of temperature, typical of hepatic abscess.

6. While jaundice was a constant feature it was of little diagnostic value.

7. The conclusion drawn is that metastatic abscess of the viscera may be caused by suppurative diseáse of the middle ear.

\title{
DISEASES OF THE LARYNX AND CONTIGUOUS STRUCTURES.
}

\author{
UNDER THE CHARGE OF \\ J. SOLIS-COHEN, M.D., \\ of philadelphia.
}

Pelliculous Sore-throats.-The profession has long been aware of the existence of various pelliculous sore-throats which were not diphtheria, and these have caused considerable confusing controversy. Bacteriologic investigation is gradually differentiating these affections. One variety, now known as Vincent's angina, has been the subject of careful study during the latter half of the present decennial. An excellent summary of what is known about this form of pelliculous sorethroat has been written by DR. RANDLE C. Rosenberger (American Medicine, July 23, 1904), who reports in addition two cases of Vincent's angina and one of noma in which the organisms characteristic of the former affection were found. Dr. Thomas H. Harris (ibid.), of New York, reports two cases, and discusses a differential diagnosis under the caption "Primary Ulceration of the Tonsil," together with some remarks on tonsillar ulceration in general. DR. G. C. CRANDALL, of St. Louis (Journal of the American Medical Association, July 23, 1904), reported a case of Vincent's angina and stomatitis at the late meeting of the Section on Stomatology of the American Medical Association. The patient was a medical student in fairly good health, with throat, mouth, and teeth in good order. The affection began in the tonsil and palate, and extended to the gums in consequence of cleansing of the teeth by a dentist on the fourth day of the disease.

Adrenalin in Malignant Disease of the Throat.-DR. ATMAR RAOUlT, of Nancy, reports (Revne hebdomadaire de laryngologie, d'otologie et de rhinologie, Juillet, 1904) a case of a man, aged sixty-eight years, whose right tonsil had in great part been removed by excision. Subsequent developments evincing malignancy, treatment with applications of adrenalin hydrochlorate, 1:1000, were instituted. While almost complete elimination of the tumor was eventually accomplished under the action of the adrenalin, serious cedema of the entire region had been 
produced, including the anterior and posterior pillars, the uvula, and a great portion of the soft palate, so that the applications of adrenalin had to be abandoned temporarily. The patient was lost sight of, but was found to have died a few weeks after cessation of the treatment.

Primary Tuberculous Growth of the Nasal Septum.-At a recent meeting of the Laryngological Society of London (Journal of Laryngology, Rhinology and Otology, August, 1904) Dr. SMurthwaire. showed a microscopic slide from a growth removed from the anterior portion of the cartilaginous septum on the right side of a woman, aged thirty-five years. The tumor was bluish-white and very uneven in surface. It was readily removed with a Volkmann spoon. The cartilage was then scraped bare, and the surface rubbed thoroughly with lactic acid solution, 75 per cent. Three months after treatment there had been no signs of recurrence.

As shown in the slide, the nature of the growth was undoubtedly tuberculous, for, though no bacilli were found, a number of giant-cells were seen to be present.

Carcinoma of the Nose.-At the late meeting of the Laryngological Society of London (Journal of Laryngology, Rhinology and Otology, August, 1904) Dr. FeIrx SEMon showed a case of papilliferous columnar-celled carcinoma of the nose in a young man, aged twenty-four years. The patient had been sent to Sir Felix in consequence of recurrences after removal of a cauliflower growth from the region of the left meatus, and which apparently sprung from the septum high up from beneath the cribriform plate. Examination of specimens of the original growth showing it to be a papilliferous columnar-celled carcinoma, by advice of Sir Felix Semon, Sir Victor Horsley performed a very radical operation, as follows: He first ligated the external carotid, then, after plugging the rhinopharyngeal cavity, he did a Rouge operation, and removed the greater part of the bony septum, the left middle turbinate, and the ethmoid on the left side up to the cribriform plate. The operation occupied nearly two hours, but so far as could be judged succeeded in completely removing the growth with a healthy area a round it. The patient made an uninterrupted recovery, and there had been no recurrence.

Cancer of the Ethmoid.-Dr. Marcer Lermoyez (Annales des maladies de l'oreille, du larynx, etc., Juillet, 1904) reports a case of cancer of the ethmoid in a man, aged forty-five years, which he removed after external exposure by resecting not only the nasal process of the upper jaw, but also the nasal bone proper, except its anterior border and the nasal spine of the corresponding frontal bone. This enabled him to expose the ethmoid frontally, instead of obliquely, as when access is made by way of the orbit. The growth, which on inspection through the natural passages was-supposed to be the size of a nut, was found to be larger than an egg. It occupied the entire ethmoid, extending in front of the agger nasi, where it would have been totally impossible to reach it by way of the natural passages. The tumor was easily rcmoved with the large ethmoidal forceps of Luc, which permitted its extraction in large fragments without notable hemorrhage. As there were no prolongations, its total ablation was practicable. The patient made a 